\title{
English Writing Course Designs Integrating into Ideology and Politics Based on Product-Oriented Approach
}

\author{
Yan Liu, Jinghuo Zhang \\ College of Foreign Languages Education and International Business, Baoding University, Baoding, China \\ Email: 406068102@qq.com
}

How to cite this paper: Liu, Y., \& Zhang, J. H. (2021). English Writing Course Designs Integrating into Ideology and Politics Based on Product-Oriented Approach. Creative Education, 12, 349-355. https://doi.org/10.4236/ce.2021.122024

Received: January 9, 2021

Accepted: February 6, 2021

Published: February 9, 2021

Copyright (อ 2021 by author(s) and Scientific Research Publishing Inc. This work is licensed under the Creative Commons Attribution International License (CC BY 4.0).

http://creativecommons.org/licenses/by/4.0/

\begin{abstract}
The paper explores the application of product-oriented approach by designing English writing course from three units, integrating ideological and political elements into teaching procedures. The three units have different teaching objects, design different class activities and choose different ideological and political topics according to product-oriented approach in order to examine the efficiency and fluency of teaching procedures in product-oriented approach. At the same time, the fundamental aim of fostering students' virtue and morality and entailing humanistic objectives has been realized.
\end{abstract}

\section{Keywords}

Product-Oriented Approach, Ideology and Politics, English Writing, Motivating, Enabling, Assessing

\section{Introduction}

English writing skill, as one of the basic skills of language, is paid more attention by educators of English in recent years, because it reflects English learners' comprehensive ability of language and critical thinking. However, writing courses in English major in universities have difficulties in low efficiency, unsatisfactory effects and heavy workload of assessment. In recent years, teachers for English writing courses attempt to adopt a variety of teaching methods to solve writing problems. Some teachers use task-based or project-based approaches in English writing class and get better outcomes (Xu, 2004) while students, who can be active in class, cannot use English socially and smoothly. Some teachers adopt the continuation task after reading to reduce students' writing anxiety and promote their creative thinking (Zhang \& Qin, 2020) while teachers' role of guidance and 
design are weakened and students cannot establish systematical writing structures and have difficulty in developing language skills. It is a big challenge for English writing course in English major to balance learning and using.

Moreover, English writing course can cultivate students' positive attitudes towards life, social and country. The essential criterion of measuring achievements in higher schools is whether students have virtue and morality and whether they can serve the state (The Ministry of Education, 2020). Teachers should guide students to have a deep understanding of core socialist values, traditional Chinese culture, revolutionary culture and advanced socialist culture, combining with professional knowledge. However, for a long time in colleges or universities students' political accomplishment has been attained only through ideological and political courses. Although the course can make students know about the basic principles of Marxism, recognize the national conditions fully, a part of Chinese culture and social awareness has not been fully absorbed and grasped. English majors' students and teachers usually face the culture and ideology from foreign countries when they learn the professional courses. Accordingly, it is English teachers' duty and responsibility to help students establish the correct ideological and political value and set up the Chinese stand, which can be realized in English writing course through discussion and writing over hot and serious topics.

\section{Literature Review}

Production-oriented approach, abbreviated as POA, was originated by professor Wen Qiufang in 2007 and has developed over 10 years from output-driven hypothesis, output-driven, input enabled hypothesis to production-oriented approach, which has been experimented by some scholars and improved further into the mature teaching theory.

Conceptual frame of POA includes teaching principles, hypothesis and teaching procedures (Figure 1). In teaching principles, the first principle is learning-centered principle that refers to useful teaching activities to effective study; the second is learning-using integrated principle that maintains learning and using should be connected closely; the third one is whole-person education principle that emphasizes that the aim of English teaching is not only to develop students' competence of language usage but also involve humanistic objectives, such as critical thinking, team cooperation, autonomous learning abilities and so on. Among them, teaching principles are the guiding principles; teaching hypothesis and teaching procedures are theoretical foundations; teaching procedures are methods of implementation. Teachers' intermediation (guide, design and scaffolding) is carried out in all the steps of teaching procedures. POA advocates integrating the input learning with productive use, that is to say, students use what they are learning immediately. Through selecting the topic of productive task and input materials carefully and designing the teaching activities in class ingeniously (Wen, 2015). 
Teaching Principles:

a. Learning-centered principle

b. Learning-using integration principle

c. Whole-person education principle

Teaching Procedures

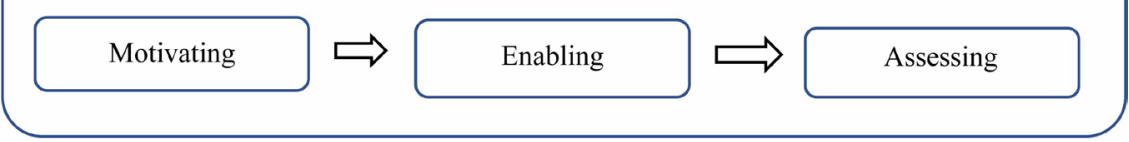

Figure 1. Conceptual frame for production-oriented approach.

Teaching procedures are the important part to guide teachers to employ objective teaching activities in English class in order to realize the aim of language communication.

1) Motivating stage is the initial step of POA. The first step in the traditional English classes usually begins with warm-up or lead-in to motivate students' interests and activate the existing knowledge while in POA it first defines the teaching objectives and inspires students to find out their knowledge gap through presenting the scenario. It includes 3 phases: teacher first presents a scenario that is possible to happen in the future job or life, which is never experienced by students but they desire to experience; students try to produce the task in English, during which they can make their difficulties and weaknesses clear; teacher illustrates the teaching objects and productive tasks, which gives students explicit learning goals (Wen \& Sun, 2020).

2) Enabling stage is the central part of POA. In this stage, teacher guides students to find out unknown knowledge, design the activities to grasp and acquire the new knowledge and build the scaffolds to help students to complete the higher-level tasks step by step (Qiu, 2020).

3) Assessing stage can be divided into two types: one is immediate assessment; the other is delayed assessment. Immediate assessments are made in class that can assist teachers to adjust teaching tempo in time and teaching progress. At the same time, delayed assessments are made after class but teachers should give the assessment criteria and demonstrate how to assess in class (Sun, 2020).

As the above shown, English writing is a way to produce the input learning effectively not only to improve students' ability of comprehensive application in language but also achieve the goal of humanity, such as critical thinking skills, autonomous learning ability, overall cultural literacy (Institution of Higher Learning of the Ministry of Education, 2007). As a foundation course in English major, English writing course needs high quality production through some knowledge input. Moreover, writing topics in the course can be wide in range and helpful in establishing correct overlooks on the world, life and value, which 
conforms to the requirements of curricula of integrated ideology and politics (Liu \& Yue, 2020).

The paper tries to present the whole teaching process of English writing classes, employing the theory and procedures in POA to achieve teaching aims.

\section{Teaching Designs for English Writing Course}

English writing teaching follows the cognitive rules from the basic elements to the whole, so the teaching process of English writing also has 3 units, that is, from the basic elements: diction and sentences, paragraphs to the whole essay. According to POA, the teaching objects are divided into 3 sub-objects, which go through 3 stages: motivating, enabling and assessing. The followings are the teaching designs for each sub-object.

\subsection{Diction and Sentences}

Plenty of words and expressions are included in English language, as many as 4000,000 words collected in Oxford English Dictionary. It is a big problem to use the proper words and expression and link them into the sentences for students learning English. This part is integrated with the topic of respecting and caring for the aged, which arouses students' attention to the aging problem of the world, aiming to enhance the sense of social responsibility and the awareness of taking the responsibility.

Sub-object 1: Students learn to use the appropriate words and expressions; make sentences unified and coherent; arouse the attention to the aged problems.

Aiming at students' writing problems of wrong and inappropriate usages of language as well as the loose and run-on sentences, the unit is provided 3 tasks in 3 stages (Table 1). Students find their language gaps and weakness in diction

Table 1. Teaching designs for the first unit: diction and sentences.

\begin{tabular}{|c|c|}
\hline Stages & Teaching Designs \\
\hline Motivating & $\begin{array}{l}\text { Task 1: Teacher gives students the productive task: assuming you would attend } \\
\text { a speech contest in your college, entitled "What should we do when the aging } \\
\text { society comes?" } \\
\text { Task 2: Students attempt to produce the speech draft and reflect on their } \\
\text { language gaps. } \\
\text { Task 3: Teacher illustrates the sub-object clearly to the students. }\end{array}$ \\
\hline Enabling & $\begin{array}{l}\text { Task 1: Students read the article The View from } 80 \text { from American writer } \\
\text { Malcolm Cowley, underlie the words and expressions about the aged and look } \\
\text { up the English interpretations and usages in the dictionary. } \\
\text { Task 2: Teacher provides some simple sentences concerning the old people } \\
\text { according to the article. Students extend the sentences using modifiers to make } \\
\text { these sentences rich in meanings and structures. } \\
\text { Task 3: Focusing on the topic of the aged society, students make the sentences } \\
\text { using the vocabulary and sentences in task } 1 \text { and task } 2 \text { one by one, making } \\
\text { sure they are related into a whole part. }\end{array}$ \\
\hline Assessing & $\begin{array}{l}\text { Task 1: Students' self-assessment on the proper interpretation in the article. } \\
\text { Task 2: Peer assessment on the sentences from the meaning and structures. } \\
\text { Task 3: Teacher-students collaborative assessment on the sentences about the } \\
\text { old people from diction, sentence unity and sentence coherence. }\end{array}$ \\
\hline
\end{tabular}


and sentences when they finish the motivating task. Teacher supplies the efficient learning material and help in due time. Through the 3 stages, students learn how to use the appropriate vocabulary and unified and coherent sentences to express in writing. In each stage, students are guided to recognize the aging problems, understand the old people's physical and mental difficulties and know how to do to treat the senior citizens.

\subsection{Paragraphs}

A paragraph is not only a whole thought unit in itself but also a part of the whole essay. It should be unified, coherent and have a full development, just like a mini-essay.

Environmental problem is one of the heated points in the world. Students have experienced the tough situation that the environmental pollution has brought but do not have clear mind in reasons, influences and solutions when they write in English. Therefore, in this part the environmental problems are picked out to raise the consciousness of sustainable development.

Sub-object 2: Students learn to write the unified and coherence paragraphs; use the specific supporting details to support paragraphs; have the awareness to protect environment.

After knowing how to use the exact vocabulary and efficient sentences, students have the basic ability to write a short paragraph. In this unit, it is essential to grasp some writing skills of paragraph and cultivate the healthy and positive attitude (Table 2). As for the environmental problems, teacher first gives a related English article as the scaffold to instruct students to analyze the writing techniques and writer's aims in each paragraph, through which students accumulate

Table 2. Teaching designs for the second unit: paragraphs.

\begin{tabular}{|c|c|}
\hline Stages & Teaching Design \\
\hline Motivating & $\begin{array}{l}\text { Task 1: Teacher gives students the productive task: Large parts of Canada are } \\
\text { recognized as one of the most polluted countries due to its mass oil industry and } \\
\text { factories. Imagine you were a representative of the new immigrants; you write to a } \\
\text { Canadian councilor to state your views on environmental problems. } \\
\text { Task 2: Students attempt to produce the letters and reflect on their problems in } \\
\text { writing a paragraph. } \\
\text { Task 3: Teacher illustrates the sub-object clearly to the students. }\end{array}$ \\
\hline Enabling & $\begin{array}{l}\text { Task 1: Students read the article Americans and the Land written by famous American } \\
\text { writer John Steinbeck, finding out the main ideas and specific illustrations and } \\
\text { examples of each paragraph. } \\
\text { Task 2: Teacher gives students all the related details on whether environmental } \\
\text { problems are too big for individuals to solve. Students provide the proper topic } \\
\text { sentence for these details. } \\
\text { Task 3: Teacher presents a topic sentence about environmental problems. Students list } \\
\text { the specific details related with it. }\end{array}$ \\
\hline Assessing & $\begin{array}{l}\text { Task 1: Teacher gives the reference answers. Students make the self-assessment. } \\
\text { Task 2: Peer assessment on the accuracy and completeness of the topic sentence. } \\
\text { Task 3: Teacher-students collaborative assessment on paragraph unity and coherence. }\end{array}$ \\
\hline
\end{tabular}


the key vocabulary and sentence expressions for preparation to write in the following step.

\subsection{The Whole Essay}

The aim of English writing course is to train the practical skills for writing short essays on lives, studies, experiences and opinions on different social phenomena. The whole essay not only needs unity and coherence but also needs writers' critical thinking and logical expression, which is one of the goals of morality cultivation in foreign language courses.

With more than 5000 years of historical and cultural precipitation, China has a very rich intangible cultural heritage. However, at present, many intangible cultural heritages are endangered, declining or even disappearing. This part tries to make students know the importance of protecting intangible cultural heritage and put forward several measures to strengthen the protection and inheritance of intangible cultural heritage.

Sub-object 3: learn to write an introduction and a conclusion, arrange the ideas in a clear logical order and expound on the practices of intangible cultural heritage protection in China.

Having acquired how to write an effective paragraph in the last unit, students will learn to write the whole essay in this unit. "Well-begun is half-done." A good introduction in an essay can attract readers' attention and lead readers to read on. Therefore, in this part teacher provides some good models of introduction to students and explains the function and writing skills of every model, which guides students to go into a smooth writing process. The enabling stage adopts the method of process writing, taking students brainstorming, mapping, outlining and drafting in groups or by themselves (Table 3 ). The series of preparation before writing help students gather all the related ideas, organize them in a clear order and outline the main structure, which practices the ability of group collaboration and critical and logical thinking.

Table 3. Teaching designs for the second unit: the whole essay.

\begin{tabular}{l} 
Stages \\
\hline Task1: Teacher gives students the productive task: Imagine you are a Chinese \\
cultural ambassador; you write an article about the practices of intangible cultural \\
heritage protection in China. \\
Task 2: Students make the presentation in class and reflect on the gaps on \\
language, structures and ideas. \\
Task 3: Teacher illustrates the sub-object clearly to the students. \\
Task1: Brainstorming and mapping. Students brainstorm the ideas on intangible \\
cultural heritage and map them in reasonable order. \\
Task 2: Teacher gives a lecture on the skills about how to write introductions and \\
conclusions. Students practice writing introduction and conclusion on the title \\
"My View on the Protection of China's Intangible Cultural Heritage". \\
Task 3: Students write the outline. \\
Task 4: Students complete the whole essay.
\end{tabular}




\section{Continued}

Task1: Teacher chooses the two samples from Students' mappings to comment in class and points out the mistakes and weaknesses.

Task 2: Teacher-students collaborative assessment and group assessment. Teacher chooses one sample from students' introductions and conclusions to assess with students in class. Students make assessment in groups.

Assessing Task 3: Teacher-students collaborative assessment and group assessment. Teacher chooses one sample from students' outlines to assess with students in class. Students make assessment in groups.

Task 4: Teacher-students collaborative assessment and peer assessment. Teacher chooses two samples from students' essays to assess with students in class. Students make peer assessment after class.

\section{Conclusion}

All in all, born in China, POA has the distinctive features and is fit for foreign language teaching in China. Authentic communicative task can solve the problem of aimless learning for English major students; Students can find out the gaps in language and cognition when attempting to make the communication.

\section{Conflicts of Interest}

The authors declare no conflicts of interest regarding the publication of this paper.

\section{References}

Institution of Higher Learning of the Ministry of Education (2007). Curriculum Requirements for Foreign Language and Literature Major in General Institution of Higher Education. Beijing: Foreign Language Teaching and Research Press.

Liu, Z. G., \& Yue, M. M. (2020). Resetting the Educational Philosophy and Restructuring Learning Content to Implement Morality Cultivation in Foreign Language Course Instruction. Journal of Foreign Language, 5, 21-29.

Qiu, L. (2020). Designing Enabling Activities in the Production-Oriented Approach: Criteria and Examples. Foreign Language Education in China, 3, 12-19.

Sun, S. G. (2020). Teacher-Student Collaborative Assessment in the Production-oriented Approach: Elaborating Principles with Examples. Foreign Language Education in China, 3, 20-27.

The Ministry of Education (2020). Guidelines for the Construction of Ideological and Political Courses in Institutions of Higher Learning. http://www.gov.cn/zhengce/zhengceku/2020-06/06/content_5517606.htm

Wen, Q. F. (2015). Developing a Theoretical System of Production-oriented Approach in Language Teaching. Foreign Language Teaching and Research, 4, 547-558.

Wen, Q. F., \& Sun, S. G. (2020). Designing Scenarios for the Motivating Phase in the Production-oriented Approach: Key Elements and Examples. Foreign Language Education in China, 3, 4-11.

Xu, F. (2004). Technology-Enhanced Tertiary English Curricular Reform. Computer-Assisted Foreign Language Education, 5, 3-11.

Zhang, L., \& Qin, T. (2020). Research on the Effects of the Continuation Task on EFL Learners' Writing Anxiety and Writing Ability. Foreign Language Education, 6, 72-76. 